\title{
DETECTION OF CRACK LOCATION AND DEPTH IN A CANTILEVER BEAM BY VIBRATION MEASUREMENT AND ITS COMPARATIVE VALIDATION IN ANN AND GA
}

\author{
M.S. Mhaske ${ }^{1}$, R.S. Shelke ${ }^{2}$ \\ ${ }^{1}$ Assistant Professor, Department of Mechanical Engineering, Sandip Foundation's Sandip Institute of Engineering \\ and Management, Nashik, Maharashtra, India \\ ${ }^{2}$ Assistant Professor, Department of Mechanical Engineering, Sir Visvesvaraya Institute of Technology, Nashik, \\ Maharashtra, India
}

\begin{abstract}
The presence of a crack is hazardous problem in the performance of many structures and it affects many of the vibration parameters like Natural frequency and mode shapes. Current research has focused on using different modal parameters like natural frequency, mode shape and damping to detect crack in beams. This work concentrates on the parameters like Deflection of a beam, Bending moment and behaviour of stresses. In this work, simulation is carried out by using analysis software ANSYS to find the change in natural frequencies as well as mode shapes for the cracked and uncracked beam. It is then verified by the results obtained from ANN controller and Genetic Algorithm. ANN is used to determine location of crack and its depth along with directions of propagation and Natural frequencies and corresponding mode shapes difference as initial input to calculate the variation and the vibration parameters. The output from ANN controller is corresponding depth and crack location. outputs from numerical analysis are compared with output from Experimentation and they have good resemblance to the results predicted by the ANN controller. Genetic algorithm is an evolutionary type of algorithm which generates the optimized solution to the problems. It is an iterative process to reach to the final solution. By using this, same results are found and related with the results of ANN. And finally the results are compared to find the most appropriate approach amongst the two methods.
\end{abstract}

Keywords-ANN, Crack, Depth, GA

$* * *$

\section{INTRODUCTION}

Damage detection by using crack analysis in a mechanical or civil structure has been a topic of research for last few decades. For every new researcher, a new method or change in modal parameters is a way to carry out the detection procedure of a crack. Damage is a result of crack and crack changes stiffness of a structure. Due to change in stiffness dynamic response of a system changes.

Finite Element Method is used to determine properties of a structure, or by modal analysis. Characteristics of cracked and uncracked beams are different. Because of this, flaws in materials can be detected, especially in beams. Crack formation due to cycling loads tends to fatigue of the structure and forms discontinuities in the crystal structure of a beam. When a structure has a crack, its dynamic properties are observed to be changed drastically. To be specific, crack reduces stiffness and natural frequencies, and increases modal damping.

Cracks can initiate major failures in vibrating component. Therefore, dynamics of cracked structures should be studied [1]. Specifically, damage due to crack can cause reduction in stiffness, with a higher reduction in natural frequencies, also increases the modal damping, and changes the mode shapes [2].Because of this changes, the crack position from support as well as edges can be found The reduction in natural frequencies can be easily noticed. In the research by Kam and Lee, the finite elements method has been selected to find the location of a crack and its magnitude for a crack in a cantilever beam. Also they have verified Natural frequency of the beam experimentally. The mathematical equations were derived for the beam with one crack and supported at both the ends [4] to observe the effect of the crack to the natural frequency. Dimarogonas and Chondros conducted many experiments with a cantilever beam made up of aluminium with a crack [5]. They stated that the experiments resemble with the mathematical expressions. Formulae were derived for bending vibrations of an Euler Bernoulli.They examined the changes in the ratio of crack location to the beam length and also the ratio of the depth of the crack to the beam height. They studied the change of natural frequency of the beam. Rizos et al introduced a method of amplitudes at two different points in a system vibrating at only one of its natural frequencies and analytical solution of its dynamic response. Shen and Chu found the presence of cracks in a structure by exciting it [9] at different natural frequencies and used a numerical method for the analysis of response. Chondros et al. [10] investigated a continuous vibration theory of a cracked beam for lateral vibration of cracked Euler-Bernoulli beams with one or two edge cracks. Determination of the dynamic response of a beam which is simply supported and has open surface cracks is done by this cracked beam theory. In this theory, the analysis of dynamic behaviour of a concrete beam with an edge crack 
was done. The effects of depth and location of a crack on the modal properties were experimentally determined in order to identify the depth and location of a crack. This method was used to give excitations to natural frequencies of the beam.

\section{EXPERIMENTATION}

When damage or crack occurs in a beam, it modifies the vibration characteristics of uncracked beam, like the natural frequencies and mode shapes. The properties of the uncracked beams are generally referred to the initial records in detection of crack. It can be determined with the help of modal tests. If compared to the initial values of experimentation, any change in the structural parameters which are measured in the service life of structure shows damage and it can be used to determine the severity of a crack as well as its location. Of all the various parameters, the most widely used parameter is natural frequency and it is used as a governing parameter of damage in a beam or structure. Also it can be verified from the modal tests with great accuracy. If a crack occurs in a beam or structure, stiffness values and natural frequency values get reduced.

Various instruments are used for experimental analysis of a crack i.e. Fast Fourier Transform (FFT) analyser, impact hammer, accelerometer, and many more accessories. The piezoelectric accelerometer which is unidirectional is used to find the functions of frequency response. The accelerometer is mounted with the help of mounting clips on the beam near crack so that it can capture correct signal. The beam is excited using an impact hammer. In every test, the location of impact is kept constant. A gentle tap is given to the beam with the help of impact hammer. Number of experiments is performed on a cantilever beam made up of mild steel having single crack and without crack . The depth as well as location of a crack is varied along the length of the beam. Following are the properties of mild steel,

Young's modulus (E) $2.0 \mathrm{e} 11 \mathrm{~N} / \mathrm{m} 2$

Density $(\rho) 7950 \mathrm{~N} / \mathrm{m} 3$

Poisson's ratio 0.3 .

The cantilever beams under experimentation have rectangular cross section.

The cross sectional area is

$0.025 \times 0.010 \mathrm{~m}$,

$\mathrm{L} \quad=\quad 0.25 \mathrm{~m}$

Crack depth is represented in terms of $(\mathrm{a} / \mathrm{h})$ ratio

Where,

$\begin{array}{lll}\mathrm{a} & = & \text { depth of crack and } \\ \mathrm{h} & = & \text { height of beam }\end{array}$

And crack location is represented in terms of (e) where e is ratio of location of crack at distance L1 from the support to the length of the beam L.

The FFT Analyzer is a tool developed for vibration measurement. It uses impulse execution \& either frequency domain analysis or time domain analysis to give the model Parameter from the response measurement in real time.

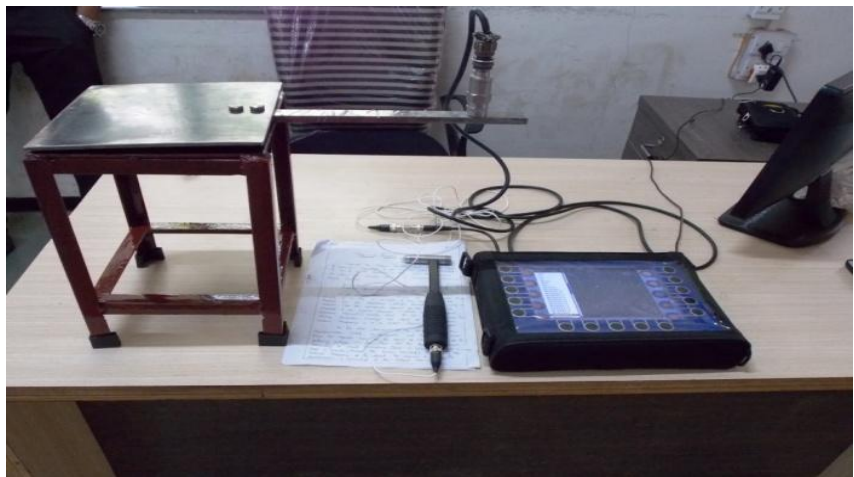

Fig.1 Experimental set up

The variable parameters considered for the experimentation are 1) depth of a crack \& 2)location of a crack from fixed end of a beam.

For a crack at $25 \mathrm{~mm}, 50 \mathrm{~mm}, 100 \mathrm{~mm}$ from fixed end of a beam, depth is varied in order to obtain number of natural frequencies and change in natural frequencies which is further useful to obtain network in ANN and population of GA.

Following are the observations of experimentation. The readings listed below are selected set of readings.

TABLE I EXPERIMENTAL OBSERVATION OF NATURAL FREQUENCY

\begin{tabular}{|c|c|c|c|c|c|c|}
\hline $\begin{array}{l}\text { Sr. } \\
\text { No }\end{array}$ & $\begin{array}{l}\text { Location } \\
\text { of Crack } \\
\text { from } \\
\text { Support } \\
\mathrm{L}_{1} \\
(\mathrm{~mm})\end{array}$ & $\begin{array}{l}\text { Depth } \\
\text { of } \\
\text { Crack } \\
\text { a } \\
(\mathrm{mm})\end{array}$ & $\begin{array}{l}\text { Ratio } \\
(\mathrm{a} / \mathrm{h})\end{array}$ & $\begin{array}{l}\mathrm{E}= \\
\mathrm{L}_{1} / \mathrm{L}\end{array}$ & $\begin{array}{l}\text { Natural } \\
\text { Frequency } \\
\text { of beam } \\
\mathrm{F}_{1} \\
(\mathrm{~Hz})\end{array}$ & $\begin{array}{l}\text { Natural } \\
\text { Frequency } \\
\text { of beam } \\
\mathrm{F}_{2} \\
(\mathrm{~Hz})\end{array}$ \\
\hline \multirow{3}{*}{1} & \multirow{3}{*}{25} & 2 & 0.2 & \multirow{3}{*}{0.1} & 446.21 & 2301.68 \\
\hline & & 3 & 0.3 & & 458.23 & 2359.34 \\
\hline & & 5 & 0.5 & & 496.27 & 2364.12 \\
\hline \multirow{3}{*}{2} & \multirow{3}{*}{50} & 2 & 0.2 & \multirow{3}{*}{0.2} & 587.19 & 2370.93 \\
\hline & & 3 & 0.3 & & 621.31 & 2389.24 \\
\hline & & 5 & 0.5 & & 637.14 & 2408.51 \\
\hline \multirow{3}{*}{3} & \multirow{3}{*}{100} & 2 & 0.2 & \multirow{3}{*}{0.4} & 658.96 & 2413.63 \\
\hline & & 3 & 0.3 & & 677.33 & 2456.98 \\
\hline & & 5 & 0.5 & & 697.67 & 2487.53 \\
\hline
\end{tabular}

From the readings obtained after experimentation, a parameter is to be defined or selected for comparison of results and its validation. And the parameter is ratio of frequencies. It is the ratio of natural frequency of a cracked beam to the natural frequency of uncracked beam. For this ratio a beam without crack is initially checked for first two natural frequencies in hertz. The values obtained for first two natural frequencies are $719.61 \& 2489.51$ respectively. 
TABLE II: RESULTING FREQUENCY RATIO

\begin{tabular}{|c|c|c|c|c|}
\hline $\begin{array}{l}\text { Sr. } \\
\text { N } \\
\text { o }\end{array}$ & $\begin{array}{l}\text { Location } \\
\text { of Crack } \\
\text { from } \\
\text { Support } L_{1} \\
(\mathrm{~mm})\end{array}$ & $\begin{array}{l}\text { Depth } \\
\text { of Crack } \\
\text { a } \\
(\mathrm{mm})\end{array}$ & $\begin{array}{l}\text { Frequenc } \\
\mathrm{y} \text { Ratio } \\
\mathrm{F}_{\mathrm{C}} / \mathrm{F}_{1}\end{array}$ & $\begin{array}{l}\text { Frequency } \\
\text { Ratio } \\
\mathrm{F}_{\mathrm{C}} / \mathrm{F}_{2}\end{array}$ \\
\hline \multirow{3}{*}{1} & \multirow{3}{*}{25} & 2 & 0.62 & 0.92 \\
\hline & & 3 & 0.64 & 0.95 \\
\hline & & 5 & 0.69 & 0.95 \\
\hline \multirow{3}{*}{2} & \multirow{3}{*}{50} & 2 & 0.81 & 0.95 \\
\hline & & 3 & 0.86 & 0.96 \\
\hline & & 5 & 0.89 & 0.97 \\
\hline \multirow{3}{*}{3} & \multirow{3}{*}{100} & 2 & 0.92 & 0.97 \\
\hline & & 3 & 0.94 & 0.99 \\
\hline & & 5 & 0.97 & 0.99 \\
\hline
\end{tabular}

\section{ARTIFICIAL NeURAL NETWORK}

Artificial Neural Networks (ANN) has been widely used as a reliable tool for determination and classification of faults in a machine or a structure. It can give solutions for inverse variation problems in fault detection as it is well prepared for the recognition of pattern and excellent capabilities of interpolation.

ANN gives a methodology to classify the problems which are related to the non-linear problems, provided that they can be represented in terms of input patterns, and it can also eliminate the complications by conventional methods of computation.

It has a set of data as inputs and the possible expected outputs are calculated by setting up a formulated and reference linearity between the set of inputs and the respective outputs. The relation between input data and output is not specified but it has to be obtained. Once the process of mapping between input and output is understood, the outputs can be easily obtained. It ultimately increases the efficiency of complete design. The purpose of using the neural network is only to calculate the outputs of all the neurons from network. Every output as a neuron is to be considered as a function of the sum of the inputs plus a bias. In the figure only one neuron is taken into consideration. The techniques like artificial neural network, Fuzzy logic and Genetic algorithm are widely used to predict the life of various components. Also they are used to optimize and minimize the errors occurred in the natural frequencies determined by various approaches like numerical simulation and experimental analysis. Genetic algorithms are basically dependent on the natural genetics and the nature selection of defined problems. Large, discrete and non linear type of modeling can be done using such techniques. Even the conventional methods fail sometimes to provide proper outputs; in such cases use of the genetic algorithm gives desired results. Genetic algorithm uses every error to evaluate the fitness and fineness of every individual step in the available population. Genetic algorithms are used for various optimizations and it is proven as an excellent solution even for very difficult problems related to optimization. The current work includes Genetic Algorithm as a solution to validate the crack detection problem with experimental results [28]. The artificial neural network is an evolutionary algorithm which is used for simulation for various cases [29]. The Current work concentrates on the application of ANN to determine the location and depth of a crack. The ANN requires a set of input data to proceed for the simulation. Hence the provided input is successive mode shapes and the corresponding natural frequencies of a cracked beam. The cantilever beam under study has cracks at several locations from the supports and various values of depths are also considered. This Search technique uses most of the data for calculation and rest is kept aside for validation which is done further. Along with the experimental results natural frequencies and mode shapes are obtained with the help of finite element method. The results of FEM are used to run ANN. The network proceeds towards the parameters for calculation by its algorithms. It then selects the Major input parameter on its own form the available data. It performs various iterations to eliminate the errors and reaches to the solution [31]. The network has number of layers for calculation. According to the given inputs, when a system enters single crack, network sets up two layer network. Similarly for two cracks it sets up a three layer network and so on. The errors go on decreasing with the increase in number of layers. Number of layers can also be selected manually. Lesser the errors more are the accuracy in outputs.

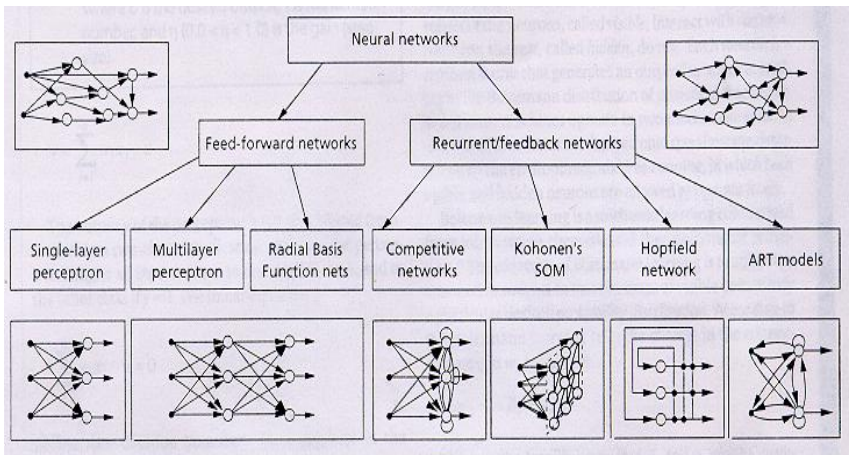

Fig. 2 Schematic network of ANN

According the topology of artificial neural network mentioned in the diagram shown above and the listed procedure, Readings required for the validation are obtained by creating a network in software known as GMDH Shell. It has given tremendous resemblances of values with the reference values. 
TABLEIII: RESULTS BY ANN

\begin{tabular}{|c|c|c|c|}
\hline $\begin{array}{l}\text { Sr. } \\
\text { No }\end{array}$ & $\begin{array}{l}\text { Location of Crack from } \\
\text { Support } \\
\text { (mm) }\end{array}$ & $\begin{array}{l}\text { Ratio } \\
\mathrm{a} / \mathrm{h}\end{array}$ & $\mathrm{E}=\mathrm{L}_{1} / \mathrm{L}$ \\
\hline \multirow{3}{*}{1} & \multirow{3}{*}{25} & 0.19 & \multirow{3}{*}{0.11} \\
\hline & & 0.31 & \\
\hline & & 0.53 & \\
\hline \multirow{3}{*}{2} & \multirow{3}{*}{50} & 0.18 & \multirow{3}{*}{0.19} \\
\hline & & 0.31 & \\
\hline & & 0.52 & \\
\hline \multirow{3}{*}{3} & \multirow{3}{*}{100} & 0.21 & \multirow{3}{*}{0.42} \\
\hline & & 0.33 & \\
\hline & & 0.51 & \\
\hline
\end{tabular}

It is a computational method and has a very large number of simple processing units called as neurons. Every neuron is assigned with a significant value as input when it is in the initial layers and outputs when it is in the cross over network.

\section{Genetic AlgorithM}

The Genetic algorithm is a technique which deals with science of genetic. Every genetic algorithm has to pass through the three basic steps namely reproduction, Crossover and Mutation. To start with the algorithm, an initial population is to be generated. Every member of the population is called as chromosome and it is a binary string. The elements of the chromosomes in particular are called as genes. In order to solve a problem of any kind, initially a code is to be generated for every string. The string variables are used to calculate the results in terms of an objective function. Once the objective function is defined, Chromosomes are to be assigned and selected for the reproduction process. Every genetic algorithm has a fitness value and it is defined in terms of more number of reproductions. A linear scaling method gives good fitness values. So it can be used in many cases. The crossover process begins after the process of reproduction. Number of crossovers is obtained with the sets of reproduction values. And the various points of crossover are selected. The chromosomes of initial process are termed as parent elements and the binary strings are called as children or offspring elements. Last process with the strings is Mutation process. By the provided codes in the algorithm some of the chromosomes are alternately changed like $O$ is replaced by 1 , or vice versa. This is a very rare process, and hence done at a low rate.

The four evolutionary elements of Genetic Algorithm are:

1. Selection: It is the process to select the parent strings and it has a direct proportion of performance of strings with total performance.The method used for selection is called as wheel of fortune.It's a random process.

2. Crossover: It is the process of interaction and mating of the input parent elements to exchange their individual strings.
3. Mutation: It Deals with the interacted parent strings to generate the offspring or children elements possessing the properties or output strings for both the parent strings. It has a great convergence toward the solution.

4 Encoding: It is the mapping process to identify the behaviour of artificial string from the available strings.

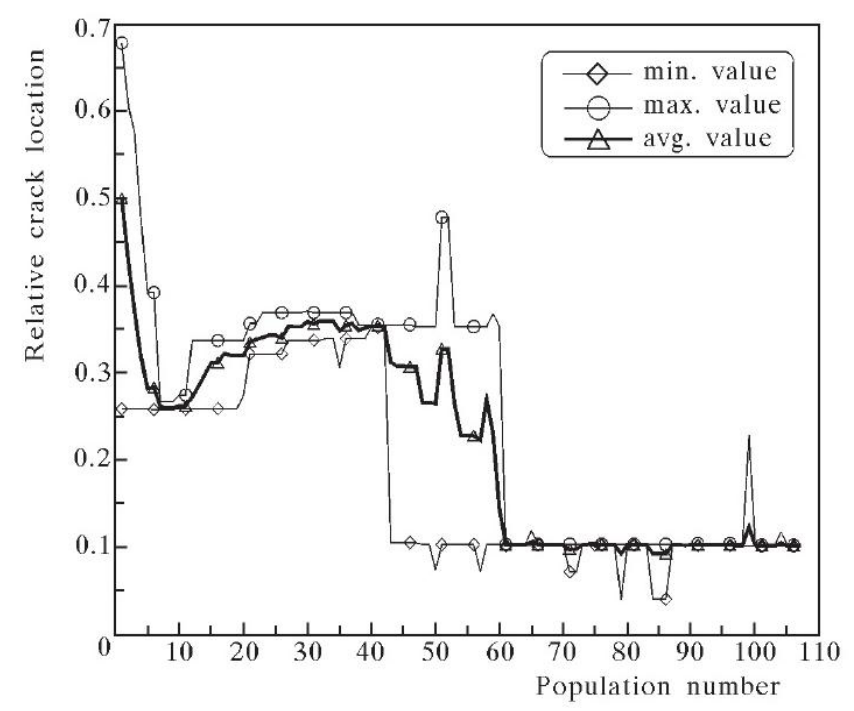

Fig.3 Graph representing Relative Crack Location by Population of GA

Its Easy enough to encode the data for further validation. The only thing is to have trained in codes of Mat lab.So, the values of parameters are to be found out by using the procedure enlisted above. And it is supported and verified by a software KEEL and Mat Lab. KEEL is a software tool to assess evolutionary algorithms which can also be used with the codes similar to mat lab.

TABLE IV : COMPARISON OF CRACK PROPERTIES BY EXPERIMENTATION, ANN AND GA

\begin{tabular}{|c|c|c|c|c|c|c|c|}
\hline $\begin{array}{l}\text { S. } \\
\text { N. }\end{array}$ & $\begin{array}{c}\text { Locatio } \\
\mathrm{n} \text { of } \\
\text { Crack } \\
\text { from } \\
\text { Suppor } \\
\mathrm{t} \\
\mathrm{L}_{1} \\
(\mathrm{~mm})\end{array}$ & $\begin{array}{c}\text { Ratio } \\
\text { a/h } \\
\text { (Expt) }\end{array}$ & $\begin{array}{l}\text { Ratio } \\
\text { a/h } \\
\text { (ANN) }\end{array}$ & $\begin{array}{c}\text { Ratio } \\
\text { a/h } \\
(\mathrm{GA})\end{array}$ & $\begin{array}{c}\mathrm{E}= \\
\mathrm{L}_{1} / \mathrm{L} \\
(\text { Expt) }\end{array}$ & $\begin{array}{c}E= \\
L_{1} / L \\
(A N N)\end{array}$ & $\begin{array}{c}E= \\
L_{1} / L \\
(G A)\end{array}$ \\
\hline \multirow{3}{*}{1} & \multirow{3}{*}{25} & 0.2 & 0.19 & 0.2 & \multirow{3}{*}{0.1} & \multirow{3}{*}{0.11} & \multirow{3}{*}{0.1} \\
\hline & & 0.3 & 0.31 & 0.31 & & & \\
\hline & & 0.5 & 0.53 & 0.5 & & & \\
\hline \multirow{3}{*}{2} & \multirow{3}{*}{50} & 0.2 & 0.18 & 0.19 & \multirow{3}{*}{0.2} & \multirow{3}{*}{0.19} & \multirow{3}{*}{0.2} \\
\hline & & 0.3 & 0.31 & 0.3 & & & \\
\hline & & 0.5 & 0.52 & 0.5 & & & \\
\hline \multirow{3}{*}{3} & \multirow{3}{*}{100} & 0.2 & 0.21 & 0.2 & \multirow{3}{*}{0.4} & \multirow{3}{*}{0.42} & \multirow{3}{*}{0.41} \\
\hline & & 0.3 & 0.33 & 0.31 & & & \\
\hline & & 0.5 & 0.51 & 0.5 & & & \\
\hline
\end{tabular}

\section{RESUlTS AND CONCLUSION}

1. For a vibrating shaft or a structure, the only parameter which can be used for various analyses is the natural frequency of vibration.

2. The Calculation terms for this work were depth of a 
crack from surface and its location from fixed support.

3. It is first found with the help of an experimental set up and then validated with the help of modern search techniques like Artificial Neural Network and Genetic algorithm.

4. Validation of experimental results with ANN has an acceptable resemblance. The indicative figures can state it in $1 \%$ to $3 \%$ of the comparison.

5. Further it has been observed that GA also generates a set of population as an output to achieve almost all the values with a variation of $1 \%$.

6. Thus, It can be stated from the work that GA can be the Accurate search method to obtain desired results for vibrating structures or beams.

\section{ACKNOWLEDGMENT}

I would like to thank hereby all the anonymous researchers, scientist for their valuable assistance.

\section{REFERENCES}

[1]. Baviskar P.R. and Tungikar V.B., Multiple cracks assessment using natural frequency measurement and prediction of crack properties by artificial neural network, International Journal of Advanced science and technology, Vol. 54, May 2013.

[2]. L. Rubio, "An efficient method for crack identification in simply supported Euler-Bernoulli beams", ASME Journal of Vibration and Acoustics, vol. 131, (2009), 051001-6.

[3]. M. Karthikeyan, R. Tiwari and S. Talukdar, "Development of a technique to locate and quantify a crack in a beam based on modal parameters", Journal of Vibration and Acoustics, vol. 129, (2007) June, pp. 395-401.

[4]. M. Kaouk, D. C. Zimmerman and T. W. Simmermacher, "Assessment of damage affecting all structural properties using experimental modal parameters", ASME Journal of Vibration and Acoustics, vol. 122, (2000) October, pp. 456-463.

[5]. P. Cawley and R. A. Ray, "Comparison of natural frequency changes produced by cracks and slots", Journal of vibration, Acoustic, stress and reliability in design, vol. 110, (1988), pp. 366-370.

[6]. S. G. Taylor and D. C. Zimmerman, "Improved experimental ritz vector extraction with application to damage detection", ASME Journal of Vibration and Acoustics, (2010) February, 011012-10.

[7]. J. M. Montaliao and E. Silva, "Experimental dynamic analysis of cracked free-free beams", Experimental Mechanics, (1990), pp. 20-25.

[8]. T. G. Chondros and A. D. Demarogonas, "Vibration of a cracked cantilever beam", Journal of vibration and Acoustic, vol. 120, (1998), pp. 742-746.

[9]. R. Routolo, "Damage assessment of multiple cracked beam: numerical results and experimental validation", Journal of Sound and Vibration, vol. 206, no. 4, (1997), pp. 567-588.

[10]. J.-J. Sinou, "Experimental study on the nonlinear vibrations and NX amplitudes of a rotor with a transverse crack", ASME Journal of Vibration and Acoustics, vol. 131, (2009) August, 041008-6.

[11]. Y.-H. Seo, C.-W. Lee and K. C. Park, "Crack identification in a rotating shaft via the reverse directional frequency response functions", ASME Journal of Vibration and Acoustics, vol. 131, (2009) February,

[12]. S. Masoud Al Said, "Crack identification in stepped beam carrying rigid disk", Journal of Sound and Vibration, vol. 300, (2007), pp. 863-876.

[13]. W. T. Springer and K. L. Lawrence, "Damage assessment based on structural response function", Experimental Mechanics, (1998), pp. 34-37.

[14]. M. A. Mohinuddin and Y. A. Khulief, "Dynamic response analysis of rotor bearing systems with cracked shafts", Journal of Mechanical Design, (2002), pp. 690-696.

[15]. Y. Narkis, "Identification of crack location in vibrating simply supported beams" Journal of Sound and Vibration, vol. 172, no. 4, (1994), pp. 549-558.

[16]. Y. Liang and H. Jialou, "An integrated approach to detection of cracks using vibration characteristics", Journal of Franklin Institute, vol. 330, no. 5, (1993), pp. 841-853.

[17]. S. E. Olson, M. P. DeSimio and M. M. Derriso, "Beam Forming of Lamb Waves for Structural Health Monitoring", ASME Journal of Vibration and Acoustics, vol. 129, (2007) December, pp. 730738.

[18]. S. Christides and A. D. S. Barr, "One dimensional theory of cracked Euler Bernoulli beams", International Journal of Mechanical Science, vol. 26, no. 11-12, (1984), pp. 639-648.

[19]. R. Y. Liang and F. K. Choy, "Detection of cracks in beam structures using measurement of natural frequencies", Journal of Franklin Institute, vol. 328, no. 4, (1991), pp. 505-518.

[20]. S. K. Maiti and D. P. Patil, "A method of analysis for detection of multiple cracks in beams based on vibration", The scientific journal advances in vibration engineering, Universities Press (India) Pvt. Ltd., vol. 3, no. 4, (2004), pp. 348-369.

[21]. Q. S. Li, "Vibratory characteristics of multistep beams with an arbitrary number of cracks and concentrated masses", International journal of Applied acoustics, vol. 62, (2001), pp. 691-706.

[22]. D. P. Patil and S. K. Maiti, "Detection of multiple cracks using frequency measurements", International journal of engineering fracture mechanics, vol. 70, (2003), pp. 1553-1572.

[23]. P. N. Saavedra and L. A. Cuitino, "Crack detection and vibration behavior of cracked beam", International Journal of Computers and structures, vol. 79, (2001), pp. 1451-1459.

[24]. B. P. Nandawana and S. K. Maiti, "Detection of location and size of crack in stepped cantilever beams based on measurements of natural frequencies", Journal of Sound and Vibration, vol. 203, no. 3, (1997), pp. 435-446. 
[25]. A. K. Pandey and M. Biswas, "Damage detection from changes in curvature mode shapes", Journal of Sound and Vibration, vol. 145, no. 2, (1991), pp. $321-\quad 332$.

[26]. W. M. Ostachowicz and M. Krawczok, "Analysis of the effect of cracks on the natural frequencies of cantilever beam", Journal of Sound and Vibration, vol. 150, (1991), pp. 191-201.

[27]. S. S. Naik and S. K. Maiti, "Solution for coupled vibrations of short and long circular shafts / beams with two arbitrary oriented open cracks", The scientific journal advances in vibration engineering, Universities Press (India) Pvt. Ltd., (2012), vol. 11, no. 1, pp. 27-45.

[28]. H. Nahvi and M. Jabbari, "Crack detection in beams using experimental modal data and finite element model", International Journal of Mechanical Sciences, vol. 47, (2005), pp. 1477-1497.

[29]. J. Xiang and Y. Zhong, "Crack Detection in a shaft by combination of wavelet based elements and genetic algorithms", International Journal of solids and structures, vol. 45, (2008), pp. 4782-4795.

[30]. H. Bechtler, M. W. Browne, P. K. Bansal and V. Kecman, "Neural networks - a new approach to model vapour-compression heat pumps", International Journal of Energy Research, vol. 25, (2001), pp. 591-599.

[31]. M. Hosoz, H. M. Ertunc and H. Bulgurcu, "Performance prediction of a cooling tower using neural network", International Journal of Energy Conversion and Management, vol. 48, (2007), pp. 1349-1359.

[32]. S. A. Kalogirou, "Applications of artificial neuralnetworks for energy systems", International Journal of Applied Energy, vol. 67, (2000), pp.17-35. 